\title{
Imprint cytology in immunocytochemical analysis of oestrogen and progesterone receptors of breast carcinoma
}

\author{
H J HELIN, J J ISOLA, M J HELIN, M J HELLE, K J E KROHN Department of Biomedical \\ Sciences, University of Tampere, Finland
}

SUMMARY Cytological imprint material from 26 mammary carcinomas was stained with monoclonal antibodies to oestrogen and progesterone receptors in an immunoperoxidase procedure. The staining result was compared with that of parallel stainings of frozen tissue sections of the same tumours. The peroxidase reactions in both techniques were semiquantitatively assessed (histoscore). In both sets of stainings the results agreed in 25 of 26 cases (oestrogen receptor: 19 positive, six negative; progesterone receptor: 14 positive, 11 negative). The histoscores of imprint preparations and cryostat sections showed a significant correlation in linear regression analysis (oestrogen receptor: $r=0.755, p<0.001$; progesterone receptor: $r=0.740, p<0.001$ ).

Imprint cytology is simple, does not require expensive instruments, and no separate specimen has to be sequestered. It is especially suitable for immunocytochemical steroid receptor analysis of small breast carcinomas.

Modern techniques for the detection of breast tumours such as mammography have resulted in the removal of carcinomas of smaller size and earlier clinical stage than before. To ensure that sufficient tissue is submitted for final morphological evaluation of paraffin wax embedded tissue, separate tissue samples are often not taken from such small tumours for steroid receptor assay by the radioligand method. For the same reason, frozen section, histopathological examination is often omitted. ${ }^{12}$ Immunohistochemical analysis of oestrogen and progesterone receptors, made possible by the development of monoclonal antireceptor antibodies, can be reliably made only on frozen sections. ${ }^{34}$

This study describes the results of immunocytochemical steroid receptor analyses of breast carcinoma imprints, prepared from cut surfaces of freshly removed tumours. To test the validity of the method, the results were compared with those of similar immunoperoxidase stainings carried out on parallel frozen sections.

\section{Material and methods}

Material was obtained from 26 women with mammary carcinoma and from 17 women with benign

Accepted for publication 6 April 1989 breast lesions, including one fibroadenoma and 16 cases of fibrocystic disease. The median age of the patients with malignant disease was 66 years (range 45-85 years) and the age of those with benign disease 44 years (35-58). Histologically, one of the carcinomas was of the mucinous type, one medullary, three were invasive lobular, and the remaining 21 were of the invasive ductal type.

Within 15 minutes of removal the tumour was macroscopically examined, dissected, and the imprint prepared by pressing the cut surface against a microscopic slide pre-coated with poly-L-lysine. The imprint was fixed immediately with absolute acetone $\left(-20^{\circ} \mathrm{C}\right.$, one minute) followed by absolute methanol $\left(-20^{\circ} \mathrm{C}\right.$, one minute). The imprint slides were stored air-tight at $-80^{\circ} \mathrm{C}$ until stained (maximum of three weeks). A tissue block was taken from the same cut surface, sectioned in a cryostat, and stored similarly until stained. Before immunoperoxidase staining the imprint preparations were post-fixed in $2 \%$ paraformaldehyde $\left(20^{\circ} \mathrm{C}\right.$, two minutes). The immunocytochemical stainings for oestrogen receptor and progesterone receptor were performed as previously described in detail. ${ }^{5}$ The demonstration of oestrogen receptor was done using the ER-ICA kit (Abbott Laboratories, Diagnostic Division, Chicago, Illinois, USA) according to the manufacturer's instructions. Progesterone receptor was detected by use of a 
mouse monoclonal anti-PR antibody ${ }^{6}$ (Transbio, Paris, France). Bound anti-PR antibodies were visualised by the avidin-biotin-complex technique (Vectastain ABC kit, Vector, Burlingame, California, USA). Only those cryostat sections containing malignant tissue $(n=26)$ were stained for comparison with the imprint preparations.

The staining results in both imprints and cryostat sections were semiquantitatively assessed. ${ }^{57}$ Each stained section or imprint preparation was given a score calculated from the formula:

$$
\Sigma(\mathrm{i}+1) \times P_{i} \text {, }
$$

where $\mathrm{i}=$ nuclear staining intensity (range: $1-4$, $0=$ no staining) and $P_{i}=$ percentage of stained carcinoma cell nuclei. On the basis of our earlier results from immunohistochemical analysis of frozen sections, scores of $\geqslant 100$ (oestrogen receptor) or $\geqslant 40$ (progesterone receptor) were considered to be positive. $^{5}$

Agreement between the oestrogen receptor and progesterone receptor statuses determined by the two different methods was tested with the $\kappa$ statistic. ${ }^{8}$ Correlation between the imprint and section histoscores was assessed by the linear regression analysis. The data were calculated with the BMDB software library (BMDB, Los Angeles, California, USA).

\section{Results}

All imprint preparations from malignant tissue were representative, containing malignant epithelial cells isolated or in clusters (fig 1). Imprints from benign breast lesions were representative in five cases, scant or borderline representative in 11 , and not representative in one case.

One imprint from fibrocystic disease was positive for oestrogen receptor (histoscore 100); all the remaining benign imprints were negative for both receptors.

Positive immunoreactivity was confined to the nuclei of imprinted carcinoma cells. Both the staining intensity and distribution of positively stained nuclei were heterogeneous (fig 1). The staining results of the two different techniques were in excellent agreement. In 25 of the 26 tumours the oestrogen receptor status was concordant (19 positive, six negative), one tumour was oestrogen receptor positive in the imprint and negative in the cryostat preparation $(\kappa=0.903)$. The progesterone receptor status was similarly concordant in 25 of 26 cases (14 positive, 11 negative; $\kappa=0.903$ ). One carcinoma was progesterone receptor positive in the cryostat section and negative in the imprint.

The mean oestrogen receptor histoscore was 183 (1 SD) 106 in the imprint preparations and $188(133)$ in

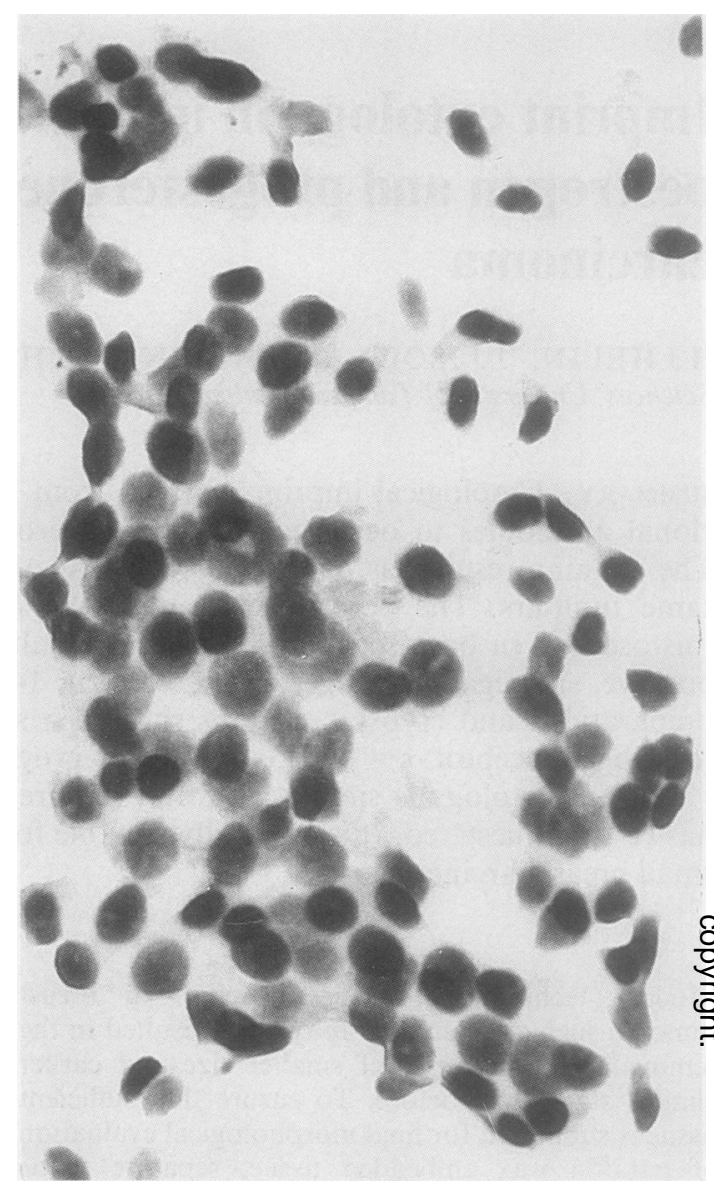

Fig 1 Imprint preparation of an invasive ductal carcinoma of the breast stained by the immunoperoxidase technique with monoclonal antibodies to oestrogen receptor.

the frozen sections. These histoscores were highly significantly correlated in linear regression analysis (fig 2). Corresponding mean progesterone receptor histoscores were 147 (136) (imprints) and 138 (138) (frozen sections). The progesterone receptor histoscores also displayed a highly significant linear correlation (fig 2).

\section{Discussion}

In our tumour material the staining results, expressed either as steroid receptor status or semiquantitative histoscores, agreed well in the imprint and frozen section preparations. This result could be expected 


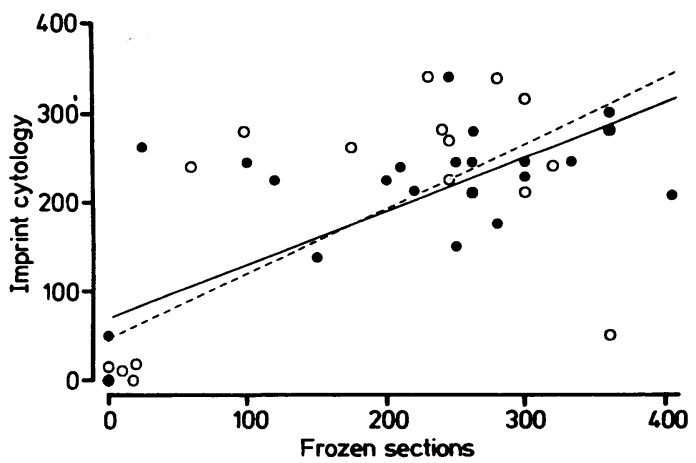

Fig 2 Correlation between semiquantitative immunocytochemical estimates of oestrogen (, and progesterone receptor ( $0,-\ldots+\ldots)$ contents in frozen sections and imprint preparations. The results are expressed as histoscore units (0-500). Linear regression analysis: oestrogen receptor, $r=0.755, p<0.001$; progesterone receptor, $r=0.740, p<0.001$.

for the following reason. Positive reactions with oestrogen receptor and progesterone receptor antibodies are seen almost exclusively in breast carcinoma cells. ${ }^{3-5}$ Due to their poor cohesion, malignant cells are easily detached when preparing the imprint. Therefore several imprints from benign lesions in our study were not representative and all except one were negative for steroid receptors. The immunocytochemical analysis in imprint preparations can thus be focused on the essential tissue component-malignant epithelial cells. Morphological details of the cell material can be easily evaluated by parallel staining with the Papanicolaou or Giemsa methods.
Compared with oestrogen receptor and progesterone receptor immunocytochemistry of frozen sections or fine needle aspirates, the imprint procedure is technically simple and does not require expensive instruments like cryostat microtomes or cytocentrifuges. The technique is recommended for steroid receptor analysis when frozen section immunocytochemistry or steroid binding assay can not be performed because of small specimen size.

\section{References}

1 Schnitt SJ, Silen W, Sadowsky NL, Connolly JL, Harris JR. Ductal carcinoma in situ of the breast. $N$ Engl $J$ Med 1988;318:898-903.

2 Sinclair RA, Pedersen JS. Screening for breast cancer. Lancet 1988;ii: 1198.

3 Helin HJ, Helle MJ, Helin ML, Isola JJ. Immunocytochemical detection of estrogen and progesterone receptors in 124 breast carcinomas. Am J Clin Pathol 1988;90:137-42.

4 Logeat F, Vu Hai MT, Fournair A, Legrain P, Buttin G, Milgrom E. Monoclonal antibodies to rabbit progesterone receptor: Crossreaction with other mammalian progesterone receptors. Proc Natl Acad Sci USA 1983;80:6456-9.

5 King WJ, De Sombre ER, Jensen EV, Greene GL. Comparison of immunocytochemical and steroid-binding assays for estrogen receptor in human breast tumors. Cancer Res 1985;45:293-304.

6 Press MF, Greene GL. Localisation of progesterone receptor with monoclonal antibodies to the human progestin receptor. Endocrinology 1988;122:1165-75.

7 McCarty KS Jr, Miller LS, Cox EB, Konrath J, McCarthy KS Sr. Estrogen receptor analyses. Correlation of biochemical and immunohistochemical methods using monoclonal antireceptor antibodies. Arch Pathol Lab Med 1985;109:716-21.

8 Fleiss J. Statistical methods for rates and proportions. New York: John Wiley and Sons, 1981.

Requests for reprints to: Dr Heikki J Helin, Department of Biomedical Sciences, University of Tampere, PO Box 607, SF-33101 Tampere, Finland. 